\title{
Content marketing strategy and its impact on customers under the global market conditions
}

\author{
Monika Poradova ${ }^{1, *}$, \\ ${ }^{1}$ University of Zilina in Zilina, Faculty of Operation and Economics of Transport and \\ Communications, Department of Economics, Univerzitna 8125/1, 01003 Zilina, Slovakia
}

\begin{abstract}
The marketing world is a dynamic and constantly changing environment that never stagnates. The purpose of this paper is to decide, based on the analysis of presented issue, how important is global marketing strategy for communication with customers. Presented paper consists of four parts, the first part of paper focuses on theoretical aspects of global content marketing. The second part focuses on methods of data collection that are needed to perform analysis and it is also the base for the fourth part of paper. The third part of paper focuses on the results of analysis, which used Spss program and discussions. In the results and discussion section, we used t-test of the mean values of the two dependent variables. The fourth part consists of conclusion, most appropriate ways and recommendations for development of global marketing strategy in the global market. The result of this paper is comprehensive overview of how global content marketing strategy can be used to influence user interests and how important is in communication with customers. It uses methods of statistical analysis, comparative methods and also synthesis and other methods of formal logic
\end{abstract}

\section{Introduction}

An essential element of marketing has always been communication and promotion of products or services. It has been verified to be their crucial price. In the past, but also nowadays, it is mostly about attracting customers' attention with the use of mass advertising, often in several places at once. Promoting products or services through largescale mass messaging has become key for business brand. [1] It is possible to maintain customer loyalty, that focuses on employees, who are interested in participating in society. [2] In the promotion process, businesses need to think that published content must also be promoted, so for long-term success it is appropriate to use the three pillars of promoting content marketing. The first pillar of content marketing is the basic minimum of promotion, the second pillar is active promotion and the third pillar is active promotion for advanced users. The notion or definition of content marketing is not unambiguous and world experts have not yet agreed on unification. Generally, content marketing is defined as the art of communicating with our customers without selling anything to them, because it is a form of forced marketing. [3]

\footnotetext{
*Corresponding author: monika.poradova@fpedas.uniza.sk
} 
Content marketing is well-known marketing method whose popularity is steadily rising with technological advancement and Internet development over the last few years. As the outdated marketing forms on the Internet became unattractive and dazed, a new way of marketing come, using content to help, enjoy and educate Internet users. Effective content marketing is based on a well-designed content strategy. An integral part of the strategy is to determine the right forms of the content. [4]

Defined content marketing creates or organizes also other than product content. It is informative, educational, or entertaining content and is published by the business at customer contact points. [5] It seeks to attract their attention and so customers know as much about a particular business as possible. We can say that content marketing is the sum of all modern online marketing strategies and quality content is just one part of the entire content marketing cycle. Content marketing is a long-term strategy where results can be seen about up to several months, in some cases after years of work. The most common task of content marketing is to attract paying customers, so you need to find out which content works best. The largest tool for measuring sales methodology is Eloqua.com or Marketo.com, which have this feature integrated in themselves, but also using Google Analytics. [6] Customers search for different kinds of information and therefore, the focus is on articles on various topics that are published on websites or other online sites. Content marketing includes voice search, where up to $50 \%$ of consumers are currently using voicecontrolled technology. [7]

Some years ago, content was primarily searched for with keywords, while long tail phrases are in common today, respectively. the whole questions. Therefore, when you promote your brand, you need to make sure that the content you create answers the questions that potential customers search most often. Arguably, to best utilize content marketing tactics for lead generation purposes, a company would need to employ marketing automation or other IT tools to allow a quick response to online queries. More specifically, the tool should allow the company to categorize and rank leads so that the sales representatives can respond to the most profitable leads instantly. [8] The concept of implemented marketing strategies has evolved over the last two centuries. However, we must not forget that implemented marketing strategies also changing with the process of globalization, technical progress and changes in customer requirements. [9] Video publishing is a particularly popular type of content publishing, but they also include infographics that are $96 \%$ successful. Video is now an integral part of content marketing. Social networks such as Facebook and other paid search platforms prefer videos, as the engagement rate is much higher. [10] Currently, up to 55\% of Internet users consume video content regularly. Potential customers also search for information on discussion forums, listen to podcasts that have a $92 \%$ success rate. Therefore, the essence is to create content not only thematically but also formally. The least used content types include content applications that account for only $31 \%$ of existing enterprise applications.

Another key challenge in the case of content marketing is that new topics emerge frequently due to emergence of new concepts and consumer interests, increasing the range of tags necessary to accurately capture the content collection. Moreover, algorithms are usually trained specifically on the type of content that they are subsequently applied to predict or classify, rather than considering the multichannel environment. For instance, an algorithm applied to website content is not necessarily expected to be effective across channels that vary in content-type, such as when classifying online videos whose titles and descriptions tend to be considerably scarcer than website content such as news and blog articles. [11]

The presented paper consists of four parts, the first part of the article focuses on the theoretical aspects of the issue of global content marketing. Second part of paper focuses on the methods of data collection that are needed to perform the analysis and also the 
background for the third part of paper. The third part of paper focuses on the results of the analysis, which we did, using Spss and discussions. In the results of the analysis we used the $t$-test of the mean values of two dependent variables. Dependent, because they consist of the same users. The fourth part consists of the conclusion of most appropriate ways and recommendations for the development of a global marketing strategy in the global market.

\section{Methodology}

The purpose of this article is to analyse whether content marketing has an impact on customers' interest in published content, and then evaluate the power of content marketing strategy. In order to achieve the headline target, it was necessary to set several sub-targets:

- Customer analysis

- Analysis of the type of content promotion

- Analysis of communication with customers

- Customer interest analysis

The first partial goal was to analyse customers, where we also used an account in Google Analytics. The survey was attended by 156 respondents. As part of the demographic data, we have an overview of users in the representation of women and men in the following figure. 1 and figure. 2 we have the age range of the most frequent users of the website.

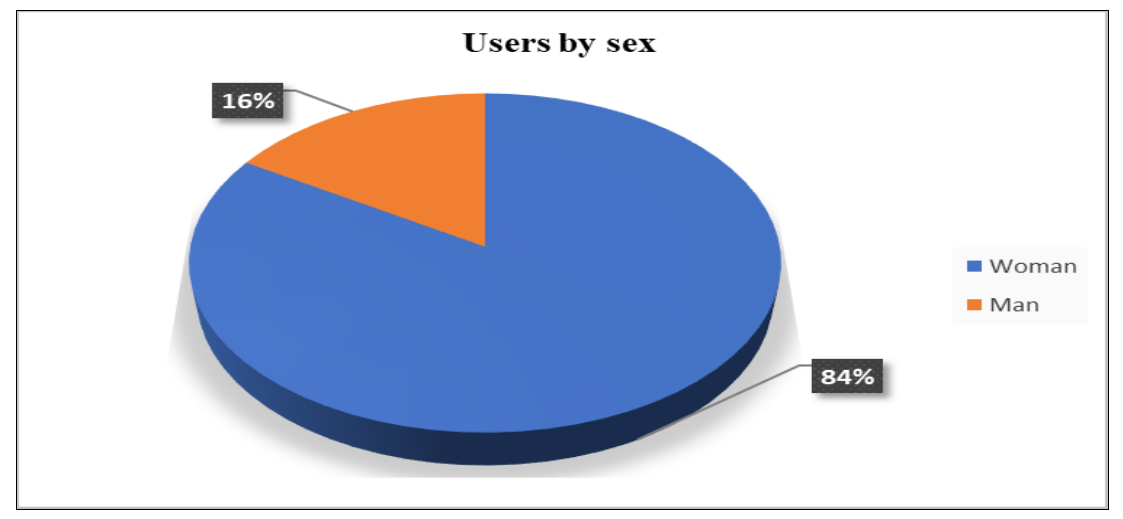

Fig. 1. Representation of women and men

From the above figures we can conclude that the largest target group is women, who make up $83.8 \%$, while men make up only $16.2 \%$, 


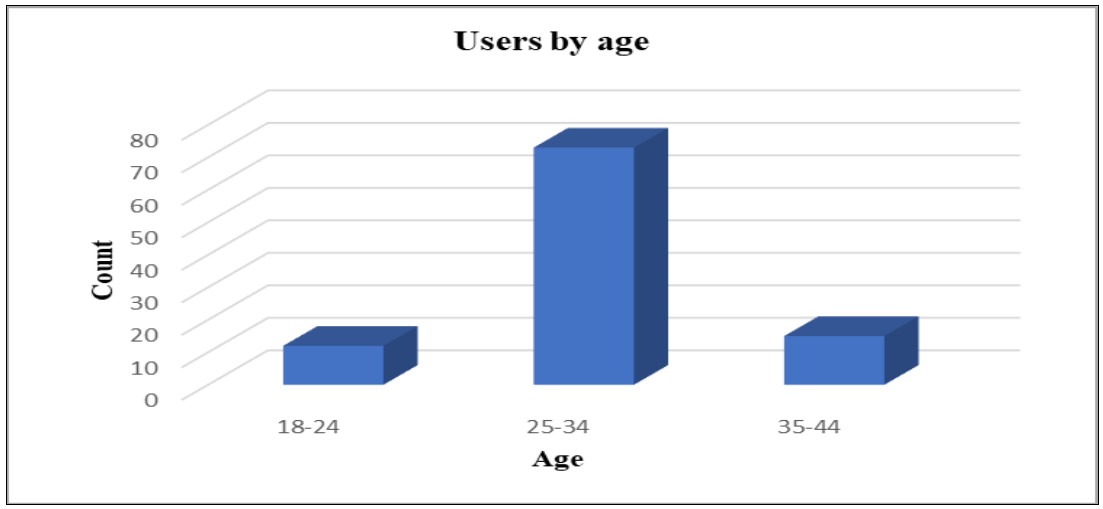

Fig. 2. User age range

Within the age range, the largest users of a website are between the ages of 25 and 34 , which is approximately $73 \%$. The second largest age category is users aged 34-44 who make up approximately $15 \%$ and the third least numerous are users in the 18-24 age group who make up approximately $12 \%$.

The second partial goal was to analyse the type of social content promotion that we also analysed using Google Analytics. The most common use of content promotion is shown in Fig. 3

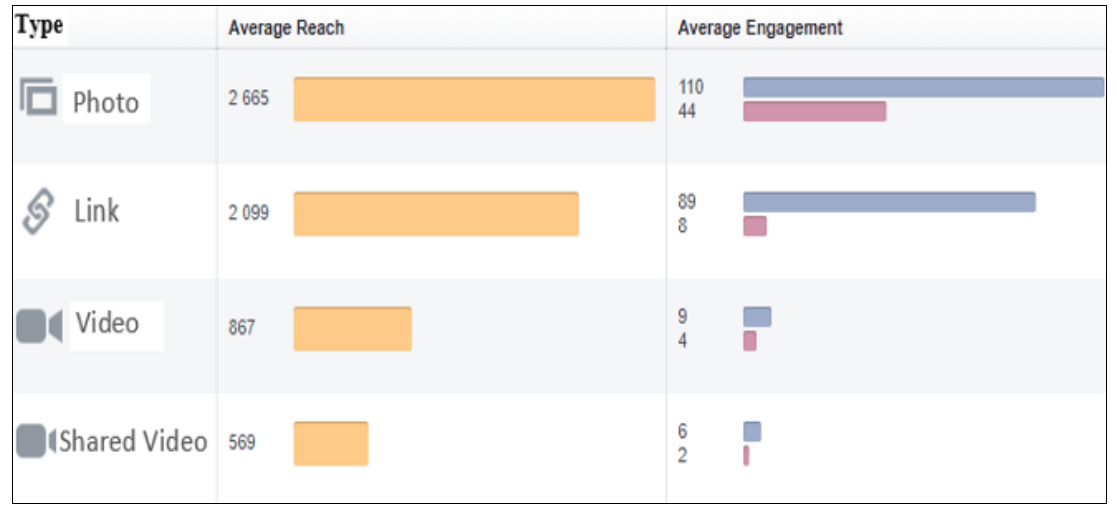

Fig. 3. Types of content promotion

The most common type of promotion is through photos, links, videos, and shared videos. The third partial goal was to analyse communication with customers.

In the following fig. 4 we see an effort to maintain communication with users through responses, comments, and sharing. 


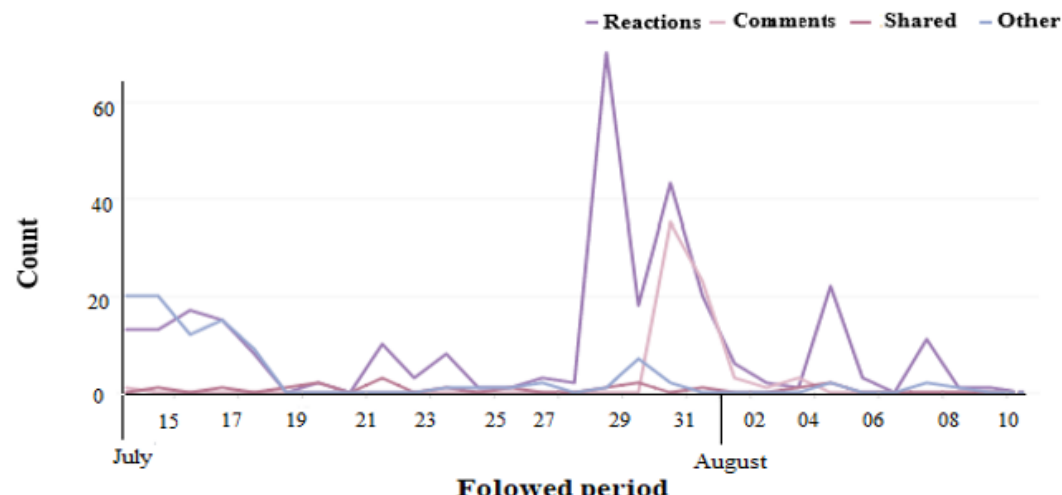

Fig. 4. Communication with users

From the above figure 4 it is clear that the most frequent communication used by the project is active response and commenting. An important role in content marketing is to know the interests of website users and, as a result, we can bounce into content creation.

The analysis of customers' interests was carried out between 28th July 2019 and 14th August 2019. The analysis of customer interests was the last step and the largest category of interests in the total sum of respondents as of July 28, 2019 is "Travel", the second largest group in the total sum is "News / Politics" and the third largest group in the total sum of interests is Arts and entertainment. The most numerous categories of interests as of 14 August 2019 is "Traveling", the second largest group is "Catering" and the third largest group is "Employment / Work". In the survey, we asked ourselves the research question: "Does a content marketing strategy affect the interests of website users?" We conducted the survey using the t-test of the mean values of two dependent files because they were the same website users. In this paper, we focused on representative selections in which results can be generalized to the general population. The first step needed was to determine the range so that the permissible estimation error was not more than $10 \%$, the confidence interval was $95 \%$ and the variability was $5 \%$. In research question no. 1 , we set the main assumption:

H1: We assume that properly designed content marketing strategy affects the interests of users. At the beginning we first set the zero assumption: $\mu 1=\mu 2$, resp. $\mu 1-\mu 2=0$ thus there is no link between the interests of website users and the impact of a content marketing strategy. We set an alternative assumption to zero assumption: $\mu 1>\mu 2$, resp. $\mu 1-\mu 2>0$ and, therefore, the interest of website users is growing through the impact of a marketing content strategy. The results of the hypothesis performed are shown in Table 1 below.

\section{Results and Discussion}

Based on a survey conducted to analyse the impact of content marketing on customer interests in a crowded global marketplace, the following can be noted.

In the following Table 1. we can see the calculated values for the reference period. 
Table 1. The results hypotheses

\begin{tabular}{|c|c|c|c|c|c|c|c|c|c|}
\hline \multicolumn{10}{|c|}{ Paired Samples Test } \\
\hline & & \multicolumn{5}{|c|}{ Paired Differences } & \multirow{3}{*}{$\mathrm{t}$} & \multirow[b]{3}{*}{$\mathrm{df}$} & \multirow{3}{*}{$\begin{array}{l}\text { Sig. }(2 \\
\text { tailed) }\end{array}$} \\
\hline & & \multirow[b]{2}{*}{ Mean } & \multirow{2}{*}{$\begin{array}{c}\text { Std. } \\
\text { Deviation }\end{array}$} & \multirow{2}{*}{$\begin{array}{l}\text { Std. Error } \\
\text { Mean }\end{array}$} & \multicolumn{2}{|c|}{$\begin{array}{l}95 \% \text { Confidence } \\
\text { interval of the } \\
\text { Difference }\end{array}$} & & & \\
\hline & & & & & Lower & Upper & & & \\
\hline $\begin{array}{l}\text { Pair } \\
1\end{array}$ & $\begin{array}{l}\text { July - } \\
\text { August }\end{array}$ & 5,067 & 9,968 & 2,574 & $-0,453$ & 10,587 & 1,969 & 14 & 0,069 \\
\hline
\end{tabular}

Source: own collaboration

From the table 1. we can see that July-August is a new variable, which is the difference of the original variables. With the help of the SPSS program and subsequent substitution into the formula we got an identical value of 1,969 . In the t-division tables we find the critical value against which this calculated value of $\mathrm{T}$ is compared: $\mathrm{t} 2 \alpha(\mathrm{n}-1)=\mathrm{t} 0,10(14)$ $=1,7613$. Subsequently, we check whether the inequality $\mathrm{T}>\mathrm{t} 2 \alpha(\mathrm{n}-1)$ is valid and thus $1.969>1.7613$. Based on the test result, the inequality holds. We reject the zero assumption at a significance level of $\alpha=0.05$ and accept the alternative assumption that there is an increase in the interest of website users through the impact of a marketing content strategy. In creating valuable content articles as well as in making social contributions, we can consider these interest categories as inspiration, as interests are not only limits, but also offer alternatives to expanding content to new topics.

We must not forget that the chosen content based on the selected interests should conceptually fit into the content marketing strategy, because it is reflected in the relationship between enterprise and other market participants and its perception in the eyes of its customers. [12] Collected data are used to support the claim that collecting information from socially proximate sources may be instrumental in legitimating the accuracy of information distributed on social networks. [13]

Some accessories are needed to increase customer interest and they are also asset for new customers gain. The first way to increase this chance is to implement a sidebar, located next to the content on the page. The sidebar should typically include elements such as a subscription form, third-party product advertising, links to the latest, popular articles, and sharing buttons. The second way is to provide at least a classic content sharing button that should be located at the end of the content. Other ways include implanting social comments, pop-ups, infographics, interviews, Link baiting, video hosting, presentations or offering "something" for free. [14]

Global content marketing is currently attracting so much attention because its importance in modern internet marketing is increasingly widespread, as is also confirmed by google, who is trying to fight and publish quality content. [15] The differences in the use of global content marketing today compared to the past are mainly due to technologies and their capabilities. [16] Almost everyone can publish interesting content over the Internet, and businesses are trying to become media themselves, because traditional forms of marketing are harder to quantify and lose strength in the digital era. For all social networks the advantage is that they can be more accurately measured and their value tells a certain popularity and authority of the site. [17] If measurements are taken for each post posted to social networks and the content is shared many times, this affects the interests of users and there is also a good chance of attracting new users. The forms of measurement also as well as the number of completed forms, registration or newsletter subscriptions, the number of comments below the content. The easiest way to measure is to create a subpage for each visitor's action on the page, which can only be accessed by filling out the contact form. [18] 


\section{Conclusion}

We can summarize the key ideas of global marketing in the next few ideas. The first idea is that content is an essential element of innovative marketing strategies. Today, content is quickly created, distributed and promoted through blogs and social networks. Advertising teams use this to their advantage through content marketing global content. Nowadays there are many blogs and websites whose main goal is to provide the information and solutions that the customer is looking for and needs, whether in the form of products, lists, etc. Internal communication is also included in the core idea of global content marketing. Teamwork is the greatest prerequisite for the global success of content marketing. Communication will also strengthen cooperation between employees each other and business management.

Another key idea of global marketing is strengthening customer relationships with fourpaper global content marketing. After establishing strong ties between team members, it is also necessary to establish a personal connection between company employees and customers. We include the planning of a global content marketing strategy in the first fourideas global content marketing. In collaboration with stakeholders and regional authorities, it will identify target customer segments and the most popular topics that customers were interested in. In the second order is creating content according to the planned global content marketing strategy. Market research is useful not only to reveal what customer is interested in, but also what kind of customer promotion you are interested in. Once the content is created, the next step is to distribute the promotion across different channels. Social networks are the most suitable modern distribution channel to reach the largest target group of customers. While traditional distribution channels such as television and newspapers are still the most effective way to reach older target audiences. Applying the first three key ideas of global marketing requires the final step to continually improve the global content marketing strategy. By reaching out to our customers, we can get feedback on what they liked, respectively. that would help in improving the strategy and to optimize its impact.

Global content marketing strategy is currently considered a sensible and effective choice, as evidenced by studies, foreign research, as well as publications by renowned experts. For start-up brands and projects, a high-quality content marketing strategy is an adequate and appealing alternative. Entrepreneurship provides extensive opportunities for creation, publishing, interesting and valuable content. The actual process of creating a content marketing strategy is quite complex and time consuming, requiring expertise and practice. When creating a content marketing strategy, we must not forget the main fact and the fact that strategy creation is not a short-term business and content marketing needs to be taken care of continuously. Content marketing also needs to be adapted to internal market changes and incorporated into the overall marketing strategy.

This paper was prepared with the support of VEGA 1/0210/19 Research of innovative attributes of quantitative and qualitative fundaments of the opportunistic earnings modelling which authors gratefully acknowledge.

\section{References}

1. M. Pakurar, H. Haddad, J. Nagy, J. Popp, J. Olah, The Service Quality Dimensions that Affect Customer Satisfaction in the Jordanian Banking Sector. Sustainabilty, 11, 1-24 (2019)

2. S. Nolan, A. Dane, A sharper conversation: book publishers'use of social media marketing in the age of the algorithm. Media International Australia, 168, $153-166$ (2018) 
3. I. Heimbach, O. Hinz, The Impact of Sharing Mechanism Design on Content Sharing in Online Social Networks. Informations Systems Research, 29, 592 - 611 (2018)

4. L. Gajanova, Strategy of Online Marketing Based the Demographic and Psychographic Segmentation. 15th Annual International Scientific Conference on Marketing Identity Digital Mirrors Location: Slovak Acad Sci. Smolenice, Slovakia, 303 - 314 (2018)

5. J. Muller, F. Christandl, Content is king - But who is the kon of kings? The effect of content marketing, sponsored content \& user - generated content on brands responses. Computers in Human Behavior, 96, 46 - 55 (2019)

6. L. M. Baker, C. R. Boyer, H. H. Peterson, A. E. H. King, Online Opportunities: A Quantitative Content Analysis Benchmark Study od Online Retail Plant Sales. Horttechnology, 28, 516 - 523 (2018)

7. B. Balducci, D. Marinova, Unstructured data in marketing. Journal of the Academy of Marketing Science, 46, 557 - 590 (2018)

8. J. Jarvinen, H. Taiminen, Harnessing marketing automation for B2B content marketing. Industrial Marketing Management, 54, 164 - 175 (2016)

9. A. Krizanova, J. Majerova, T. Kliestik, P. Majercak, Theoretical Aspects of Brand Building in Seafood Industry. Nase more, 60, 105-112 (2013)

10. R. M. Achen, J. Kaczorovski, T. Horsmann, A. Ketzler, Exploring Off-Season Content and Interaction on Facebook: A Comparison of U.S. Professional Sport Leagues. International Journal of Sport Communication, 11, 389 - 413 (2018)

11. J. Salminen, V. Yoganathan, J. Corporan. B. J. Jansen, S. G. Jung, Machine learning approach to auto-tagging oline content for content marketing efficiency: A comparative analysis between methods and content type. Journal of Business Research, 101, $203-$ 217 (2019)

12. T. Kliestik, T. Kovacova, M. Podhorska, I. Kliestikova, Searching for Key Sources of Goodwill Creation as New Global Managerial Challenge. Polish Journal of Management Studies, 17, 144-154 (2018)

13. R. Kirby, K. Valaskova, J. Kolencik, P. Kubala, Online Habits of the Fake News Audience: The Vulnerabilities of Internet Users to Manipulations by Malevolent Participants. Geopolitics, History, and International Relations, 10, 44-50 (2018)

14. J. K. Noel, T. F. Barbor, J. J. Grady, Advertising Content, Platform Characteristics and the Appeal of Beer Advertising on a Social Networking Site. Alcohol and Alcoholism, 53, $619-625$ (2018)

15. J. Peng, A. Agarwal, K. Hosanagar, R. Iyengar, Network Overlap and Content Sharing on Social Media Platforms. Journal of Marketing Research, 55, 571 - 585 (2018)

16. A. R. C. Perinotto, R. A. De Siqueira, New Trends in Digital marketing for the Tourism sector. Turismo-Estudos E Praticas, 7, 186 - 215 (2018)

17. K. Y. Abeywardana, A. R. Ginige, N. Herath, H. P. Somarathe, T. M. N. S. Thennakoon, Hashtag Generator and Content Authenticator. International Journal of Advances Computer Science and Applications, 9, 246 - 252 (2018)

18. P. Escobedo, T. B. Curz, K. Y. Tsai, J. P. Allem, D. W. Soto, M. G. Kirkpatrick, M. Pattarroyo, J. B. Unger, Monitoring Tobacco Brand Websites to Understand Marketing Strategies Aimed at Tobacco Produckt Users and Potential Users. Nicotine \& Tobacco Research, 20, 1393 - 1400 (2018) 